\title{
Educação do MST e crise do paradigma moderno de ciência
}

\author{
RUI GOMES DE MATTOS DE MESQUITA \\ Universidade Federal de \\ Pernambuco, Recife, PE, Brasil \\ GISELE WANESSA DO NASCIMENTO \\ Universidade Federal de \\ Pernambuco, Recife, PE, Brasil
}

\section{RESUMO}

Analisamos o princípio da alternância adotado pelo Programa Nacional de Educação na Reforma Agrária (PONERA) nas práticas pedagógicas do MST- assumindo-se que tais práticas interpelam a tentativa do pragmatismo de harmonização entre indivíduo. $\mathrm{O}$ intuito foi o de perceber como esse princípio pode fazer emergirem sujeitos "criativos". A metodologia articula Maingueneau, Laclau e Mesquita. Construímos quatro categorias (elevação de potência; necessidade de relação com os meios instituídos; tensão com esses meios; desejo ideológico de universalização) e três dimensões analíticas (metodologia; espacialidade; finalidade). Com essa metodologia, analisamos dois documentos do MST (um público e outro de circulação interna ao Movimento), quatro entrevistas (militantes 1, 2 e 3 do MST e uma professora universitária), assim como artigos científicos de intelectuais orgânicos ao Movimento. Concluímos que conduzir criativamente a experiência significa romper com a noção de cumulatividade na formulação de princípios.

\section{PALAVRAS-CHAVE}

MST; experiência; alternância; produção de conhecimento. 


\section{BRAZIL'S LANDLESS RURAL WORKERS' MOVEMENT (MST) EDUCATION AND THE CRISIS OF THE MODERN SCIENCE PARADIGM}

\section{ABSTRACT}

We have analyzed the principle of alternation in the MST pedagogical practices, adopted by the National Program of Education in Agrarian Reform, in order to know - assuming those practices interpolate the attempt of pragmatism to harmonize individuals and society - how this principle can produce "creative" individuals. The methodology articulates Maingueneau, Laclau and Mesquita. We have built four categories (power elevation; necessity of establishing relations with institutional milieus; tension with these milieus; ideological desire of universalization) and three analytical dimensions (methodology; spatiality; finality). Within this methodology, we have analyzed two MST documents (one public and one restricted to MST), four interviews (3 members and a teacher), as well as scientific articles by intellectuals involved with MST. We have concluded that to conduct creatively the experience means to break with the cumulative notion of principles.

KEYWORDS

MST; experience; alternation; knowledge production.

\section{EDUCACIÓN DEL MST Y CRISIS DEL PARADIGMA MODERNO DE CIENCIA}

\section{RESUMEN}

Hemos analizado el principio de alternancia en las prácticas pedagógicas del Movimento dos Trabalhadores Rurais Sem Terra (MST),adoptado en el Programa Nacional de la Reforma Agraria, a fin de identificar -asumiendo que dichas prácticas cuestionan el intento del pragmatismo de armonización entre individuo y sociedad- cómo este principio puede hacer que surjan sujetos "creativos". La metodología empleada articula Maingueneau, Laclau y Mesquita. Hemos construido cuatro categorías (elevación de potencia; necesidad de relación con los medios instituidos; tensión con dichos medios; deseo ideológico de universalización) e tres dimensiones analíticas (metodología; especialidad; finalidad). Con base en esta metodología analizamos dos documentos del MST (uno público y otro de circulación interna del movimiento), cuatro entrevistas (Militantes 1,2 y 3 del MST y una profesora universitaria), así como artículos científicos de intelectuales orgánicos del Movimiento. Hemos concluido que conducir creativamente la experiencia significa romper con la noción de "acumulativo"en la formulación de principios.

MST; experiencia; alternancia; producción de conocimiento. 
Não é raro ouvirmos dos teóricos do campo da didática que se deve prestar mais atenção, para além das amarras estruturalistas, à singularidade que caracteriza os diferentes ambientes escolares. Alguns desses teóricos - preocupados com os mais variados temas, da superação de tipologias massificantes ("nordestinos", "negros", "pobres") (Fonseca, 1999) à "fabricação" do ambiente escolar por professores (Albuquerque; Morais; Ferreira, 2008) - chamam a atenção para o risco de se incorrer num abstracionismo que exclui do campo analítico processos educativos reais de interação. Ferraço (2008), que aposta na formação de uma cidadania contra-hegemônica, investe numa perspectiva não prescritiva de currículo, enfatizando a possibilidade de um fazer educativo crítico e criativo. Tal postura tem afinidade eletiva com a perspectiva construtivista, que, ao adotar uma ontologia relativista, presume a existência de múltiplas realidades (Denzin; Lincoln, 1994) - o que confere importância à agência na estruturação do social. Guarda, por uma perspectiva microssociológica, afinidade com uma dimensão positiva de política (Mesquita,2009), aquela que implica um encurtamento da temporalidade das narrativas políticas, ou seja, a noção de construção imediata de células da futura sociedade.

Num plano filosófico, a fenomenologia (que põe em suspensão o "mundo natural", de conotação metafísica) - na medida em que rompe com a existência de leis lógicas, sejam empíricas ou transcendentais, e traz à tona a questão da "consciência intencional” (Mora, 1978, p. 110) - conforma muito dessas teorias sociológicas, particularmente se levarmos em conta a fenomenologia social de Alfred Schutz, voltada para "o estudo do modo como as pessoas vivenciam diretamente o cotidiano e imbuem de significados as suas atividades" (Kilminster, 1996, p. 307). Nesse contexto, o "fantasma do solipcismo" ("foco 'egológico' da fenomenologia"), ligado à tradição filosófica europeia (Descartes, Kant, Husserl) e à emergência do Estado-nação com sua noção de "paz interna" (idem, p. 309-310), remete ao moderno valor epistemológico de totalidade social estável.

Contemporaneamente ao desenvolvimento das ideias de Schutz, o pragmatismo americano, que teve em Pierce uma figura central, critica o fato de Descartes "fazer da certeza de si mesmo do ego pensante o sólido alicerce de uma filosofia" (Joas, 1996, p. 599). Tenta substituir, assim, o "ego dubitativo" por uma "busca cooperativa da verdade, para superar os reais problemas da ação" (idem, ibidem). A dúvida teria uma dimensão mais criativa e fincada na realidade, na medida em que, esbarrando na resistência do mundo, deveria conduzir a tentativas de modificação deste mundo. Sua proximidade com a fenomenologia está no fato de que ambas intentam não reificar nem a realidade nem o conhecimento que dela temos. Pragmatismo e fenomenologia conformaram correntes do escolanovismo - movimento erigido sob os auspícios do liberalismo (Libâneo, 1994, p. 63-64) e corrente fundamental na estruturação do sistema nacional de ensino no Brasil.

O pragmatista John Dewey $(1971,2010)$, ao defender, no bojo de um projeto político democrático, a estreita relação entre vida e educação, traz à baila o conceito de experiência - sendo sua perpétua reconstrução e redirȩ̧ão a própria razão de ser do fazer educativo. A escola deveria ser uma espécie de pequena comunidade simplificada, responsável pela direção da experiência das novas gerações. A experiência, nesse modelo de escola, ao dialogar com o conhecimento acumulado pelas gerações 
predecessoras, estaria inextricavelmente ligada ao tecido social. A finalidade da educação seria forjar cidadãos democráticos que habitariam essas instituições, tornando-as - e a própria sociedade como corolário -, numa perspectiva construtiva, democráticas.

Experiência remete, nesse contexto, àquele papel fundamental que a agência assume na perspectiva microssociológica. A direção da experiência pela escola em Dewey (1971), voltada para o desenvolvimento de noções como "impulso", "instinto", "movimento vital" ou "força intrínseca" (essência do indivíduo), deveria articular o aspecto lógico (disciplinar, do "programa", das "matérias", como conhecimento acumulado) com o aspecto psicológico (de um indivíduo tateante). Tal articulação teria como eixo estruturante o processo, de maneira que, na metodologia proposta que não visaria atender objetivos politicos fixos -, mais importante que os resultados seriam as "experiências diretas individuais" (idem, p. 54).

O meio educativo em que se dá esse processo é considerado fundamental. Articular os polos lógico e psicológico requer, numa perspectiva deweyana,

um ambiente de integração social, de harmonização de tendências em conflito, de larga tolerância inteligente e hospitaleira. Influências antagônicas, isolamentos familiares ou religiosos, espírito de clã ou de partido, ameaçam, nas sociedades heterogêneas de hoje, a dividir, separar, desunir os membros da família social. (Teixeira, 1971, p. 25)

No movimento mesmo de tentar articular, harmonicamente, por meio da direção da experiência, indivíduo (polo psicológico) e sociedade (polo lógico), Teixeira - discípulo de Dewey - não rompe com esses polos paradigmáticos da ciência moderna, uma vez que desautoriza o investimento em meios educativos afins a interesses específicos e conflituosos na sociedade. O investimento (ideológico) para que nada venha a se interpor entre o indivíduo e a sociedade pressupõe certa homogeneidade cultural no processo de estruturação do social. Isso reforça, como se a sociedade fosse fruto de uma teia única de intersubjetividade, o foco egológico da tradição filosófica europeia, que se vincula àquela noção de paz interna do Estado-nação. Tal pressuposição, em seu desejo de articular os polos indivíduo-sociedade, não considera o conflito e a exclusão como elementos fundantes das totalidades sociais (Laclau, 2005).

Para que essa lógica conflitual não se aprisione no pessimismo convencionalmente atribuído às abordagens de matriz estruturalista, apostamos que é em um campo entrecruzado por dimensões micro e macrossociais que se pode aventar uma fuga da determinação estrutural. Essa "pista" se revela uma tentativa de superação da dicotomia sujeito-objeto - no bojo da qual a dicotomia indivíduo-sociedade é um exemplo -, entendida como um valor em crise da metanarrativa moderna (Laclau; Mouffe, 2001). Trata-se de uma tendência epistemológica que ganha visibilidade no contexto americano e europeu nos anos 1980 (hermenêutica, teoria crítica, interacionismo simbólico, pós-estruturalismo etc.) e que emerge a partir da quebra de unicidade metodológica das ciências sob a proeminência das ciências naturais (Giddens; Turner, 1999). As ciências têm então sua objetividade questionada, o que 
remete à narratividade dos modelos analíticos (Somers; Gibson, 1995) e compromete aquela tomada de "matérias" (programa) como síntese de acúmulo civilizacional. Quando a dimensão interpretativa (verstehen) é tida como constitutiva do saber científico, percebe-se, com Brockmeier e Harré (2003), a impossibilidade de fazer coincidir estrutura narrativa (epistemologia: conjunto de conceitos que se mobilizam para representar a estruturação do social) e social (ontologia: estruturação mesma dos seres e entes da sociedade).

Quando as ciências humanas se mostram receptivas a diferentes abordagens, o caráter desinteressado do saber científico (pressuposto na noção de acúmulo civilizacional) é abalado em seu tom matemático de formalidade lógica (Pessanha, 1997). Os saberes, assim, ao se aproximarem da doxa (opinião), são inevitavelmente permeados por interesses conflitantes, o que invalida pretensões como a de Teixeira: forjar um ambiente escolar livre de "influências antagônicas". Há aqui uma flagrante politização da dimensão cultural que, tensionando a noção homogênea de cultura nacional e de equivalência desta com o "popular"(Ortiz, 1999), coincide, na década de 1980, com a emergência de "novos" movimentos sociais (Sader, 1988). Inaugurando espaços e formas alternativas de luta, esses movimentos desafiam, potencialmente, o modelo liberal-representativo de democracia, assentado que está na unidade cultural do Estado-nação, na economia capitalista e no indivíduo abstrato como unidade de representação política.

Os assentamentos do Movimento dos Trabalhadores Rurais Sem Terra (MST), com suas demandas específicas (particulares), como a disputa pelo financiamento de cooperativas agroecológicas, em tensão com o modelo de desenvolvimento defendido pelo agronegócio (MST, s/d.a), parece ser um bom exemplo de emergência de subjetividades coletivas que apresentam certa desfuncionalidade em relação ao Estado brasileiro, entendido como totalidade social. Suas demandas, acedendo a experiência a uma dimensão coletiva, são bastante instigadoras no intuito de interpelarem a livre tentativa do pragmatismo de harmonização entre indivíduo e sociedade. A noção de escola "em movimento" (Caldart, 2003, 2004) - numa relação íntima com a dimensão experiencial da educação (Vendramini, 2004), em que a articulação entre os aspectos técnico-econômicos e a cultura política se consubstanciam (Andrioli, 2007) - aponta para uma politização do campo da didática; politização esta que desafia qualquer pretensa racionalidade autônoma das teorias pedagógicas.

É nesse contexto, tendo como pano de fundo a problematização do conceito de experiência, ${ }^{1}$ que nos perguntamos em que medida os Sem-Terra podem ser considerados um sujeito coletivo criativo e produtor de conhecimento. A alternância, princípio

1 Essa problematização tem como pano de fundo um diálogo com o "construtivismo". Corcuff (2001) considera que a tentativa de superação da separação entre o ideal (pensamento) e o material é uma característica convergente nas perspectivas construtivistas. Tais perspectivas, para levarem a cabo essa superação, prestam, segundo o autor, atenção aos aspectos relacionais e interativos como forma de se desvencilhar de outra dicotomia que lhe é afim e clássica na sociologia, a dicotomia entre indivíduo e sociedade. Este artigo ambiciona contribuir para a reflexão sobre processos interativos por uma perspectiva radicalmente contra-hegemônica. 
metodológico ressignificado no âmbito do MST - e adotado emblematicamente no Programa Nacional de Educação na Reforma Agrária (PRONERA), política pública desenhada, em boa medida, por intelectuais orgânicos ou próximos ao MST (Andrade; Di Pierro, 2004; Molina, 2003) -, será tratada, nesse contexto, como um exemplo de discurso criativo (no sentido de apresentar alguma eficácia social e política que se concretiza na materialidade da identidade Sem Terra).

Tangencia nossa análise a crítica do espaço escolar hegemônico, entendido, com Maingueneau (1997, p. 60), como “dispositivo de transmissão", ou seja, um espaço social que, sendo cenário material dos discursos pedagógicos, lhes é constitutivo. Ao tomar a formação de "cidadãos" como finalidade do fazer educativo, a escola oficial, que se dedica à construção de trajetórias individuais de vida, alimentaria uma forma institucional-curricular incapaz de responder aos movimentos ontológicos coletivos de estruturação do social. Não descartamos o vínculo construtivista entre experiência e estruturação social, mas propomos que este vínculo seja investigado por meio de uma dimensão coletiva.

Justifica-se, assim, a demanda "particularista" do MST, uma vez que reclama por um meio educacional diferenciado. Ao chamar a atenção para a necessidade de uma escola "do" campo - que atenda efetivamente aos interesses dos povos que aí habitam - e não meramente "no" campo (Arroyo, 2009; Caldart, 2004), a experiência desse movimento abre não somente possibilidades de estratégia política, mas também importantes picadas metodológicas. Problematizar a abordagem construtivista do conceito de experiência requer indagar o posicionamento da escola em relações mais amplas de poder, trazendo à baila uma análise fina dos constrangimentos antepostos ao desejo de universalização de quaisquer discursos.

É dentro desse espectro de preocupações que estabelecemos o objetivo deste artigo: analisar o princípio da alternância no bojo das práticas pedagógicas do PRONERA, no intuito de perceber em que termos este princípio pode fazer emergirem sujeitos políticos críticos e criativos.

Exporemos a seguir nossa metodologia e método de análise, frutos de uma articulação entre o corpus da pesquisa, conceitos da análise do discurso de Maingueneau (1997), da teoria do discurso de Laclau (2005) e a metodologia proposta por Mesquita (2010) para a análise de ações educativas contra-hegemônicas. Depois analisaremos a relação entre o sentido político pretendido com o princípio da alternância pelo MST e aspectos empíricos de sua prática pedagógica em torno do PRONERA. Teceremos as considerações finais, quando sistematizaremos elementos para redimensionar o conceito de experiência em Dewey.

A interlocução com este autor, entre uma enorme gama de filósofos que se preocupam com tal conceito, vale salientar, assume, como veremos, a forma de um diálogo tenso e propositivo. Concordamos, nesse contexto, com sua crítica anti-essencialista ao pensamento clássico grego - que confrontava "razão e experiência como se se tratasse de uma oposição eterna e infranqueável” (Jay, 2009, p. 30) -, 
corroborando a ênfase de Dewey no processo experiencial da vida cotidiana, que não poderia se valer de verdades universais apriorísticas. ${ }^{2}$

Essa ênfase no processo também está presente no discurso do MST, com a diferença, a ser explorada no desenvolvimento do presente texto, de que aqui a experiência é acedida a uma dimensão coletiva. É chamando a atenção para os efeitos desestabilizadores da experiência coletiva do MST, no que tange ao paradigma moderno de ciência, que tentaremos evidenciar como princípios educativos sacralizados por Dewey (particularmente cumulatividade e continuidade da experiência) estão presentes não apenas em nossas escolas, mas também no próprio discurso do MST. O propósito de fundo, então, é argumentar que, para potencializar "estrategicamente" a dimensão criativa do sujeito coletivo MST, ter-se-ia que romper com a noção de um sujeito coletivo coeso, que acumula conhecimento ao mesmo tempo em que dá continuidade a sua tradição; apesar de um mundo (dicotômico) que lhe impõe dificuldades.

\section{METODOLOGIA E MÉTODO DE ANÁLISE DOS DADOS}

Partimos do pressuposto de que a linguagem é "completamente atravessada pelos embates subjetivos e sociais" (Maingueneau, 1977, p. 12). Reconhecemos, por um lado, a importância da agência para a estruturação do social. Por outro lado, não reconhecemos na linguagem ou, mais especificamente, no discurso científico um recurso instrumental a ser utilizado por individuos - espécie de unidade autocentrada de orientação da experiência - no processo educativo. Ao abrirmo-nos à existência de unidades coletivas de processamento da experiência, tensionamos com a abordagem de Dewey que propõe, tomando indivíduos como pontos de mediação, articular os polos psicológico e lógico na ação de reorientação da experiência. Enfatizamos a dimensão ideológica desse investimento, entendendo como "ideológico" todo discurso que cumpre a função de promover um fechamento da totalidade social (Laclau, 2005), reificando a racionalidade que aí se encerra.

Subjetividades coletivas contra-hegemônicas como o MST não apenas não se reduzem à consciência individual, como negam a possibilidade de ampliação de processos coesos de intersubjetividade. Mas, em contraste, num contexto em que ressaltamos "um lugar de primeiro plano ao heterogêneo" (idem, p. 14), ou seja, a inelutável presença do outro em "nosso" discurso, a existência de subjetividades contra-hegemônicas pressupõe algum nível de coesão intersubjetiva. Nosso desafio é refletir - num esforço teórico de construção de nosso método de análise -, levando em conta a heterogeneidade discursiva, acerca dos processos de ampliação da

2 Não identificamos a mesma radicalidade e refino metodológicos, por exemplo, no marxismo humanista inglês, que alimenta, na sua tentativa de articular razão e experiência, certa crença essencialista no potencial criativo da classe trabalhadora (Jay, 2009). Esse "fetiche da experiência" é, conforme expressão de Martin Jay, assumido por Thompson na sua polêmica com o estruturalismo althusseriano: "A experiência, insistiu Thompson, se encontrava do lado do materialismo histórico, que conhece a resistência que opõe o mundo à mera mistificação ideológica” (idem, p. 238). 
subjetivação coletiva. Remeter a tais processos significa não renunciar à possibilidade de construir horizontes políticos estratégicos, ainda que reconheçamos, com Dewey, a inexistência de uma verdade "à espera de ser descoberta" (Teitelbaum; Apple, 2001, p. 197).

Percebemos o investimento do MST no discurso científico (ressignificando o princípio da alternância em sua prática pedagógica), na medida em que alça a experiência à dimensão coletiva, como um artifício "retórico" (Laclau, 2005), que desafia, no bojo da luta hegemônica, a racionalidade constitutiva do fechamento das totalidades sociais. Laclau, preocupado em discutir a questão do populismo, insiste numa noção positiva e produtiva de retórica (criativa). Ele nos lembra acerca da eficácia dos discursos tidos como populistas, posto que esses, igualmente ideológicos, são efetivamente capazes de materializar identidades populares. Sendo eficazes, mas, ao mesmo tempo, percebidos pelos seus opositores como expressão da mais crassa irracionalidade (MST visto, por exemplo, como "seita" particularista), esses discursos ressaltam a existência de uma "retórica generalizada... De maneira que o populismo aparece como uma possibilidade distintiva e sempre presente de estruturação da vida política" (idem, p. 27-28).

Deparamo-nos aqui com uma primeira categoria de nosso método. Trata-se do investimento na elevação da potência do sujeito coletivo com vistas à superação das resistências que o mundo concreto lhes impõe. O recurso ao gênero científico pelo MST corresponde a tal investimento na medida em que procura desfrutar um lugar de legitimidade e autoridade (Maingueneau, 1997, p. 34-39). Como se trata, entretanto, do processo de construção de um "nós” inserido, não raro, em situações de conflito, os sujeitos coletivos recorrem ao discurso científico para dar sentido a suas práticas correntes. Inserem esse gênero discursivo, e o valor de "objetividade" prevalente no mesmo, nos múltiplos processos de subjetivação que, sendo eminentemente retóricos, tendem a tensionar a própria autoridade a que recorrem.

Tais processos de subjetivação, assim, ao promoverem alterações no plano ontológico, borram o encaixe deste com a sincronia de conceitos organizados pelo discurso científico no plano epistemológico - exatamente de onde este retira o efeito ideológico de autoridade (cientificidade; objetividade). O processo educativo de redireção coletiva da experiência, ao desestabilizar o discurso científico, possibilita a utilização de muitos de seus valores numa perspectiva diacrônica, particular e contingente, que remete a tradições e memórias específicas. ${ }^{3}$ Há aqui, quando a própria linguagem científica ganha ares de narratividade, uma abertura para a possibilidade de modificação das regras que regem os processos enunciativos.

A elevação da potência dos sujeitos coletivos depende, em boa medida, da possibilidade de alteração dessas regras. Pensar as condições de possibilidade para tal alteração requer considerar, com Maingueneau (idem, p. 53-56), a existência de duas vertentes indissociáveis do discurso: a social e a linguística. Recorrer ao

3 Sepé Tiaraju dos Povos Guaranis, Quilombo dos Palmares, Canudos, Timbas e Formoso, Contestado, Cangaço e Ligas Camponesas são exemplos de "herança rebelde" reivindicada pelo MST (Caldart, 2004, p. 108). 
discurso científico requer, para além da noção de mediação entre discurso e grupo social, uma articulação com os lugares sociais ou institucionais em que se materializa esse discurso.

Quando o MST investe, no desenho metodológico do PRONERA, na construção de um "compromisso" entre governo federal, instituições de ensino e movimentos sociais e sindicais (Brasil, 2004, p. 44), ele nos faz perceber a existência da necessidade de estabelecer relaçôes com os meios instituídos (nossa segunda categoria analítica). Razões de ordem diversa concorrem para essa necessidade. Centrando nossa análise no campo educacional, destacamos duas: a) as universidades são responsáveis pela esmagadora maioria da produção científica (Santos, 2005), firmando-se como um lugar autorizado para a produção da verdade; b) os camponeses, sendo sujeitos historicamente submetidos a massivos processos de exclusão e "desqualificação" política e econômica (Caldart, 2004), tornam-se pouco potentes para dirigir sua experiência coletiva com o grau de autonomia desejável.

O paradoxo reside no fato de que, sendo as instituições regidas por regras e regularidades próprias (formações discursivas) (Maingueneau, 1997, p. 31) - que se materializam em seu "programa" (currículo) -, elas impõem constrangimentos à intencionalidade dos sujeitos que a ela se articulam. Maingueneau nos lembra de que o analista do discurso deve considerar, no exame das ideologias, as comunidades discursivas que a elas dão "suporte". A ideologia, assim, "ocupa-se, simultaneamente, da representação do mundo e da organização dos homens, tarefas que significam o direito e o avesso de uma mesma atividade" (idem, p. 60). É assim que a análise do discurso se abre, na perspectiva de Maingueneau, à possibilidade de articular formação discursiva e sociedade - epistemologia e ontologia. Essa articulação tem a ver com a desessencialização identitária dos sujeitos coletivos, na medida em que o próprio processo de direção da experiência - dando-se em articulação com comunidades discursivas sobre as quais não podemos ter autonomia e que nos impõem muito de seus valores e regras - requer que incorporemos regras de outras formações discursivas.

É por isso que a formação discursiva não deve ser considerada uma "expressão estabilizada da 'visão de mundo' de um grupo social”, ela é antes "o lugar de um trabalho no interdiscurso [...] Um domínio 'inconsistente', aberto e instável” (idem, p. 113). Essa interdiscursividade inerente ao conceito de formação discursiva nos faz entender aquela desessencialização do discurso, uma vez que este incorpora "elementos pré-construídos, produzidos fora dela [a formação discursiva], com eles provocando sua redefinição e redirecionamento" (idem, ibidem). Sendo a identidade discursiva forjada na relação com o outro (idem, p. 119-120), no bojo de comunidades discursivas cujas regras delimitam as condições de enunciação dos sujeitos, a tensão com o meio em que se dá o processo experiencial, nossa terceira categoria analítica, configura-se como um pré-requisito para a eficácia (elevação da potência do sujeito) dos discursos contra-hegemônicos.

A agência não tem uma relação de externalidade com a linguagem, usando-a como uma espécie de suporte para a materialização de uma razão/interesse previamente existente. Essa razão e esse interesse ganhariam materialidade na medida em que determinado meio social oferecesse as condições de possibilidade para sua 
emergência. Não reduzir as práticas sociais à intencionalidade, sublinhando a importância da heterogeneidade discursiva, significa considerar a relação entre o grau de liberdade (ou autonomia) para a condução da experiência e o espaço social em que emerge determinada subjetividade coletiva. A luta criativa por hegemonia, ao interditar a existência de um sistema fechado de identidades relacionais (como no estruturalismo, em que a agência é mero efeito da estrutura) (Laclau; Mouffe, 2001), está umbilicalmente ligada à construção de espaços favoráveis às experiências coletivas em curso, ampliando o leque de possibilidades de sua reorientação e, como corolário da elevação da potência do sujeito coletivo, da própria estruturação do social.

Entretanto, a articulação do polo lógico com o polo psicológico nada mais é do que expressão do trabalho retórico de redirecionamento da experiência e nunca a possibilidade de fundação de uma sociedade harmônica em novas bases. Os discursos produzidos pelas subjetividades coletivas são resultantes de experiências prévias, de maneira que o desafio que se posta é não se deixar enredar como momento interno de um processo histórico-narrativo mais amplo. Acontece que, conformados pelo valor metanarrativo moderno de construção de totalidades sociais estáveis, esses discursos tendem a apagar os traços contingentes e heterogêneos de sua própria construção, investindo, no processo de estruturação do social, num desejo ideológico de universalização.

Com a exposição dessa nossa quarta categoria analítica, fica claro que as práticas metodológicas investidas por atores coletivos para guiar o processo de redirecionamento de sua experiência, mais do que processos racionais puros, correspondem a discursos ideológicos que disputam o poder sobre a formação de regras discursivas. A metodologia, mais que uma "coisa", "tecnologia" ou "artefato" a ser utilizado na produção do conhecimento, é uma dimensão no processo de estruturação social. Ela perpassa as quatro categorias que construímos em nosso método. Ao conformar o tipo de movimentação dos sujeitos contra-hegemônicos para a obtenção de determinados fins (potencialização de sua força política), ela esbarra, por um lado, na necessidade de articulação com meios instituídos e, por outro lado, com sua capacidade de tensionar esses meios. Lida, por fim, com a impossibilidade de se ampliar como razão coerente no sentido de sua universalização.

A finalidade da ação educativa - que remete tanto ao projeto mais amplo de sociedade como às unidades de recepção dessa ação (identidades em que se investe) - está presente nos constantes momentos de redirecionamento da experiência. Esses momentos de decisão, sendo da ordem da contingência, perdem refino no caso de reificação da metodologia. Isso porque, conformados pelo desejo de universalização de seu esforço de estruturação do social, fixam-se no polo epistemológico na tentativa de harmonizar a realidade social numa estrutura conceitual. $O$ discurso metodológico, não podendo tomar como referência estável para a tomada de decisões (redirecionamento da experiência) o polo epistemológico, não se presta à função de pura "mediação" deste último com o polo ontológico. Resta ao analista reconhecer nos meios em que se dá a ação educativa, por mais concretos e materiais que sejam, outra dimensão de análise. Terceira dimensão aqui proposta, a espacialidade do social deve ser também percebida em perspectiva narrativa. A ação educativa contra-hegemônica, sendo da ordem do ideológico, ao invés de investir na mediação entre 
conhecimento e realidade social, teria que tomar como finalidade o ir realizando "o mundo que pretende descrever" (Maingueneau, 1997, p. 62-64).

É com esse método, composto de três dimensões analíticas (metodologia, espacialidade do social e finalidade da ação educativa) que perpassam quatro categorias (elevação da potência do sujeito coletivo, necessidade de estabelecer relações com os meios instituídos, tensão com o meio em que se dá o processo experiencial e desejo ideológico de universalização) que nos propomos a analisar a relação entre o sentido político pretendido com o princípio da alternância pelo MST e os aspectos empíricos de sua prática pedagógica em torno do PRONERA.

Ao formularmos categorias e dimensões de análise, estivemos construindo, referenciados em bases empíricas, nosso objeto de pesquisa. Tal construção se deu guiada por uma triangulação metodológica entre o conceito de experiência de Dewey e alguns conceitos da análise do discurso em Maingueneau e da teoria do discurso em Laclau. Segundo Uwe Flick (2004, p. 238), a importância da triangulação repousa no fato de "enriquecer e completar ainda mais o conhecimento e de transpor os potenciais epistemológicos (sempre limitados) do método individual". Na nossa perspectiva, ao proceder a triangulações em diálogo com o objeto de pesquisa, estamos pondo em xeque visões empiricistas, que tentam se apropriar com precisão da "realidade". A própria ligação entre metodologia, método e construção do objeto (Sautu et al., 2005, p. 38) denuncia tais visões, ao evidenciar a presença inevitável da subjetividade do pesquisador na construção de seu objeto.

Na próxima seção, ao analisarmos o princípio da alternância no bojo das práticas pedagógicas do PRONERA, estaremos interessados na relação entre a sedimentação de lógicas sociais (materialidade do social como efeito de hegemonia) e processos políticos de subjetivação. Procedemos, para tal, à análise de documentos do MST, artigos científicos e quatro entrevistas (militantes 1, 2 e 3 do MST e uma professora universitária).

Analisamos dois documentos do MST aos quais tivemos acesso por meio dos militantes entrevistados: um de circulação interna, que trata de aspectos estratégicos dos assentamentos e discute, nesse contexto, a articulação da educação com o projeto de economia popular do movimento; outro, de circulação externa, que esboça os princípios basilares de sua proposta educativa. $\mathrm{O}$ primeiro documento foi produzido num Encontro Estadual do MST-PE e contou com a participação de militantes do setor de educação. $\mathrm{O}$ segundo foi produzido exclusivamente pelo setor de educação do MST.

Quando os documentos são produzidos para fins de circulação interna, contam com uma menor influência direta da recepção, ou seja, minimizam a necessidade de estratégias linguísticas (recursos retóricos) destinadas a relativizar os possíveis sentidos a serem construídos quando da circulação pública do documento. Expressando o tipo de "apropriação estratégica" ideal que o Movimento faz do "discurso científico", tais documentos permitiram-nos perceber com maior nitidez o trabalho do interdiscurso na sua ação política (a presença do "outro", que evidencia um sujeito cindido; não coeso).

As entrevistas com os militantes 1, 2 e 3 do MST foram realizadas em agosto de 2010, na sede estadual da entidade em Caruaru/PE. Esses militantes - em 
posição de maior ou menor destaque na direção do MST - foram selecionados, vale frisar, por terem um engajamento direto com o setor de educação do Movimento, particularmente por terem atendido a cursos do PRONERA. Um deles é dirigente nacional do MST e exerce posição de destaque no setor de educação do Movimento. Os outros dois têm projeção apenas em âmbito estadual.

As entrevistas foram do tipo narrativa, o que possibilita aos informantes desenvolver suas considerações sobre sua experiência com o PRONERA a partir de sua própria linguagem, símbolos e estrutura narrativa (Schütze, 2010). Podemos, assim, perceber detalhes da produção de sentido, que se dão contextualmente, a depender dos valores que circulam em ambientes específicos de interação (Macedo, 2006). Perguntas imanentes e exmanentes foram realizadas quando, no desenrolar das entrevistas, nos pareceram oportunas. Tais perguntas tinham como objetivo aprofundar a compreensão de situações em que as vicissitudes e contingências do cotidiano revelam interpelações ideológicas e, nessa esteira, dão-nos pistas da heterogeneidade discursiva (presença do "outro" nos discursos, que remete à falta de coesão dos sujeitos coletivos e individuais).

A entrevista com a professora universitária foi realizada no mesmo mês de agosto e nos foi particularmente útil na medida em que ela, não tendo nenhum vínculo político ou afetivo com o Movimento, representa claramente valores liberais que circulam hegemônicos no ambiente acadêmico - com(ntra) os quais se relacionam os militantes entrevistados.

Os artigos científicos são, eles próprios, uma vez que normalmente produzidos por "intelectuais orgânicos", exemplares de um investimento mais explícito do MST no discurso científico. Há aqui, certamente, uma relação de representação política, através da qual uma vanguarda intelectual elabora e dá sentido, a partir de códigos e valores constitutivos da ciência moderna, à experiência do Movimento. Esses códigos e valores, assim elaborados (e aqui está a dimensão ontológica da representação política), estruturam, por assim dizer, a própria compreensão (verstehen) dos militantes do MST - ou seja, o escopo do horizonte discursivo que conforma a produção de sentido. É assim que percebemos a presença dos princípios da cumulatividade do conhecimento e continuidade da experiência no discurso do MST.

\section{O SENTIDO DA ALTERNÂNCIA NA AÇÃO EDUCATIVA DO MST}

A noção de experiência como processo de articulação entre o epistemológico e o ontológico perpassa o conjunto de princípios filosóficos e pedagógicos que conformam a ação político-educatica do MST. É assim que o Movimento frisa em várias passagens de seus documentos uma necessária interdependência entre teoria e prática, de maneira que os princípios

não surgiram primeiro, antes das práticas. Ao contrário, eles já são o resultado de práticas realizadas, das experiências que estamos acumulando... Podemos comparar isso com a abertura de uma picada no meio de um matagal: as primeiras pessoas vão abrindo o caminho, devagar, experimentando, quebrando galhos, desviando banhados; se estas pessoas deixam estacas, marcos, referências, isso 
se tornará guia para os próximos caminhantes, que por sua vez também poderão deixar novos marcos, abrir atalhos, refazendo a estrada e o próprio jeito de andar nela. (MST, s/d.b, p. 4, grifos nossos)

Note-se que, como no conceito deweyano de experiência, existe nessa narrativa uma intencionalidade voltada para a construção de sujeitos criativos - a diferença é, como já antecipamos, que a experiência no MST é acedida a uma dimensão coletiva, mas a noção de coesão do sujeito é mantida. Os próximos caminhantes, beneficiados pelas picadas anteriormente abertas, teriam sempre a possibilidade de deixar novos marcos, que alterem não só o sentido da estrada por meios de atalhos como o jeito de andar nela. É sobre os termos em que o princípio metodológico da alternância pode favorecer e tornar efetiva a possibilidade de se deixarem novos marcos, ou seja, a criatividade do sujeito Sem Terra, que nos propomos a refletir.

Nessa metáfora da picada, a mata assemelha-se a um mundo dicotômico, cuja resistência (matagal, galhos, banhados), sendo real e efetiva, não exerce um papel constitutivo no sentido de estabelecer os termos (o jeito ou as regras discursivas) em que os próximos caminhantes irão colocar novos marcos e abrir atalhos, refazendo a estrada. É como se o escopo da compreensão, ou seja, o horizonte desde onde a experiência é processada (expressa), permanecesse o mesmo independentemente dos deslocamentos epistemológicos e ontológicos. $\mathrm{O}$ antes e o depois da narrativa são decididos no âmbito quase exclusivo do sujeito Sem Terra, que, dotado, em dimensão coletiva, de uma consciência intencional, não terá sua identidade transmutada. Mesmo que esse sujeito politize o polo epistemológico da experiência, contaminando a sincronicidade deste com a construção dos movimentos ontológicos de sua tradição particular, contra-hegemônica, o polo ontológico continua dicotômico - uma mata que, oferecendo resistências, deve ser transpassada por um sujeito coeso. Não há, portanto, no discurso (científico) do MST, a percepção da existência de uma relação inextricável entre a espacialidade do social e as enunciações discursivas (dimensões linguística e extralinguística no conceito laclauniano de discurso). Mantém, portanto, nos marcos da metanarrativa moderna, a dicotomia sujeito/objeto.

Há uma noção de cumulatividade do conhecimento, a qual, decorrendo dessa dicotomia (que faz supor o sujeito coeso), não permite apreender que o grande legado dos primeiros caminhantes não é tanto deixar um caminho aberto para um fim prévia e intencionalmente determinado. Esse legado seria, de acordo com nossa abordagem, investir no alargamento (pragmático, ao gosto de Dewey) do grau de liberdade dos caminhantes para escolher e tornar material o que se lhes afigura como o melhor sentido e jeito de se caminhar na estrada. Tal investimento, que não significa abrir mão de dar prosseguimento às tradições a que se filiem os sujeitos coletivos, considera que a tradição mais se fortalece quando se levam em conta as condições de possibilidade para a emergência de sujeitos criativos, capazes de redefinir suas experiências sem se fixarem em procedimentos ou mesmo objetivos prévios.

Favorece essa intuição aquela percepção de que há uma relação indissociável entre conceito e contexto, o que questiona a existência dos universais (a "matéria" em Dewey) como um ato político e contingente de poder. Aquelas condições de possibilidade tornam-se favoráveis quando, como corolário da própria intervenção 
no mundo, o conjunto de princípios e regras de enunciação amplia o campo de factibilidade dos discursos.

Percebemos, nesse contexto, haver uma relação ainda não explorada politicamente na experiência do MST entre criatividade - quando se eleva a potência do sujeito coletivo - e alterações no polo ontológico, quando, tensionando-se com os meios instituídos (espacialidade), chacoalham-se as lógicas sociais (valores e afetos) sedimentadas hegemonicamente. Tal relação problematiza a existência de um efeito estético-narrativo de cumulatividade do conhecimento, que ganha força no princípio da continuidade na experiência (Dewey, 2010). Esse último princípio, ao tentar captar a perpetuação das experiências passadas nas futuras, que devem se seguir com relativo grau de coerência, pressupõe a unidade do próprio mundo (racionalidade) com o qual se debatem os sujeitos contra-hegemônicos. Unidade do mundo e continuidade da experiência são ingredientes conjuntos indispensáveis para outro efeito narrativo, a saber, o de continuidade ou coesão do sujeito que (re) direciona as experiências vividas.

O paradoxo é que, sendo os constrangimentos do mundo constitutivos da intencionalidade dos sujeitos, a única possibilidade de esses últimos se desvencilharem das lógicas sociais hegemônicas é quebrando a própria unidade do mundo. Essa quebra, por seu turno, desestabilizando a continuidade da experiência, põe em xeque a noção de sujeito como unidade coesa e estável, capaz de ir "acumulando" conhecimento/experiência. A quebra da unidade do mundo requer, na medida mesmo da alteração das lógicas sociais hegemônicas, que se abra mão de que os termos de nossas escolhas (os princípios procedimentais para a abertura de novos marcos; o "jeito de andar"), por mais acertados que nos pareçam, sejam os mesmos para os próximos caminhantes. Ou seja, para mais radicalmente se cultivar uma tradição contra-hegemônica, não deveríamos ver os sujeitos-caminhantes como unidades coesas de processamento da experiência nem querer que sigam fielmente "seus" princípios - ou aos princípios tal como decodificados (cientificamente) pelos seus intelectuais orgânicos.

Quando se quer, como é o caso do princípio metodológico da alternância, articular teoria e prática, a finalidade da ação político-educativa é permeada por valores que, circulantes nos espaços hegemônicos (instituídos), terminam por denunciar o caráter relacional das identidades, ou seja, a presença do outro em "nosso" discurso. Como corolário, mesmo que não percamos a noção estratégica de projeto, essa presença interdita aquela crença num sujeito (individual ou coletivo) coeso, que daria continuidade racional às intencionalidades primeiras.

Por contraste, podemos perceber, nesse trecho da definição dos princípios que norteiam a ação político-educativa do MST, a ausência da noção de interdiscurso, que borraria, caso presente estivesse, o efeito estético-narrativo de continuidade a partir de uma visão de mundo estável, que vai se consolidando (sabendo mais) ao longo do tempo:

Quanto mais avançarmos na formulação dos princípios, mais avançaremos na coerência de nossas práticas, construindo um sentido estratégico (com objetivos de 
longo prazo, com articulação entre as ações) para nosso trabalho e para o conjunto de nossa organização. (MST, s/d.b, p. 4, grifos nossos)

A noção de um avanço "estratégico" da relação princípio-prática, que aqui se converte em unidade organizativa, é dicotômica na medida em que - fruto de um desejo ideológico de universalização -, para expandir uma subjetividade coletiva que se quer coesa, investe numa continuidade da experiência centrada na dimensão linguística do discurso. Elide, portanto, a dimensão constitutiva daquela vertente social do discurso (extralinguística em Laclau), conforme aprendemos com Maingueneau, e que não leva em conta a dimensão espacial na análise dos processos políticos e educativos.

Podemos, a partir desse entendimento, deduzir que a noção cumulativa de avanço na formulação de princípios pode, na prática, conduzir a menos criatividade, pois nesse caso não se atenta, como o faz Dewey (2010), que o crescimento intelectual e moral decorrente das experiências anteriores se expressa na possibilidade de alterar os princípios que regem a seleção das experiências futuras. Entretanto, aquela necessidade de alteração no polo ontológico para que se abra espaço à criatividade (sensibilidade presente no MST) não é percebida pelo autor, na medida em que este toma o indivíduo como unidade de processamento da experiência. O pragmatismo de Dewey, por isso, ao contrário do sujeito coletivo MST, fica desarmado de um investimento estratégico, rendendo-se às lógicas sociais hegemônicas, uma vez que o mundo, composto por uma teia de intersubjetividades individuais, impõe-se como unitário.

Ao aceder a experiência ao plano coletivo e contra-hegemônico, o MST intui a necessidade de tensionar o meio (e seus vínculos funcionais com a totalidade social) em que se dá o processo experiencial. É assim que "o" sentido do princípio metodológico da alternância ganhou, criativamente, uma coloração política específica, não cumulativa, na prática do próprio MST - alterando (como apostava Dewey, só que no plano individual) os princípios que regem a seleção das experiências futuras em função de ações "estratégicas".

Para compreendermos a ação criativa do MST em torno do princípio da alternância, temos que conhecer um pouco a história desse princípio, ou seja, os elementos pré-construídos ou experiências prévias em torno dele. Segundo Ribeiro (2008, p. 30), a "alternância” entre trabalho produtivo e ensino já aparece, num contexto urbano, em autores como Marx, Lênin e Gramsci. O que não é estranho, portanto, ao MST, que se referencia no marxismo. A Pedagogia da alternância, em contraste, nasceu, num contexto rural, no Sudoeste da França, em 1935, através da iniciativa de pais agricultores preocupados com a formação dos seus filhos (Ribeiro, 2008). O princípio da alternância do trabalho com o tempo escolar não era, nesse contexto, aplicado à fábrica, mas à comunidade. $\mathrm{O}$ discurso universalista cristão é quem animava esse princípio metodológico, longe, portanto, do éthos marxista revolucionário. Onde reside então a ação criativa do MST?

A "alternância" estava presente no princípio da união entre ensino e trabalho, herdada pela tradição marxista dos socialistas utópicos no século XIX. Marx e Engels pensavam tal princípio no bojo de uma estratégia revolucionária, que visava 
à disputa pelo controle do processo produtivo nas fábricas (Nogueira, 1990). Com a ação de deslocamento da política do plano local ao nacional - que redunda numa "autonomização" (liberal) da esfera política e consequente despolitização da esfera econômica (Eley, 2005; Santos, 2005) -, esse princípio perde força enquanto valor ideológico, secundarizando-se na tradição marxista. O MST, que articula cristianismo e marxismo (via teologia da libertação) (Stedile, 2005), desloca o princípio da alternância do sentido cristão humanista e o ressignifica no bojo de um projeto revolucionário socialista em que o camponês desempenha um papel de suma importância.

Com isso, o Movimento insere seus assentamentos num projeto de desenvolvimento popular e socialista que, tentando desvencilhar-se das lógicas sociais hegemônicas capitalistas, volta-se para a construção de "áreas liberadas" - conforme nos explicou a militante 1. O MST investe no princípio metodológico da alternância no bojo de uma estratégia que envolve uma desestabilização do polo ontológico, apontando para o rompimento com a unidade do Estado-nação. A "alternância" é mais do que uma "estratégia de escolarização", decorrente do "abandono da educação no meio rural brasileiro"; ou uma "possibilidade de permanência do jovem no meio familiar", devido à "importância da mão de obra dos membros da família”; ou uma perspectiva de "qualificação técnica dos jovens agricultores familiares", no bojo de "uma nova lógica de desenvolvimento do campo" - sendo essas algumas lógicas e finalidades da alternância presentes na experiência brasileira, conforme Lourdes da Silva (2008, p. 108-109).

O sentido imprimido pelos militantes do MST parece ter uma finalidade mais ampla e claramente contra-hegemônica. $\mathrm{O}$ militante 1 esclarece que no bojo da demanda por uma educação do campo havia

uma necessidade dada por nosso movimento... Tanto das lideranças, das coordenações que sentiam uma necessidade de estudar, mas... Para você estudar tem que ter um processo regular de frequência, e parar para estudar parecia que não dava consonância com o processo de militância.

A militante 2, ao comentar que, além dos "cursos ligados à educação", o PRONERA começou a organizar cursos de direito e veterinária, entre outros, afirma que o referido programa contribui para o projeto anticapitalista de desenvolvimento do MST, na medida em que capacita "seu próprio povo pra conduzir seu movimento". A militante 3, por sua vez, demanda da universidade o saber "fazer com que a teoria consiga contribuir com nossa prática; e nossa prática consiga ter um vínculo com a teoria"; e mais adiante esclarece que uma turma da Via Campesina é "diferenciada de uma turma comum, porque a gente tem uma prática diferente; a gente tá sempre na luta".

A criatividade dessa ação militante em torno do princípio da alternância reside, por um lado, em romper com a moderna narrativa urbano-industrial evolucionista, que, interpelando matrizes políticas socialistas e capitalistas, prenuncia o fim do campo e do camponês (Damasceno; Beserra, 2004, p. 76). Faz-se necessário, para tal, nessa perspectiva militante, 
fortalecer a educação do campo como área própria do conhecimento, que tem o papel de fomentar reflexões que acumulem força e espaço no sentido de contribuir na desconstrução do imaginário coletivo sobre a relação hierárquica que há entre campo e cidade, sobre a visão tradicional do jeca tatu, do campo como lugar de atraso. (Molina, 2002, p. 39, grifos nossos)

O MST, ao alçar a "alternância" a um sentido contra-hegemônico - propondo-se a subverter lógicas sociais sedimentadas na modernidade capitalista, que hierarquizou a cidade em detrimento do campo-, trabalha no sentido de construir uma área de conhecimento mais autônoma, o que elevaria sua potência como sujeito político. Os constrangimentos, entretanto, que se interpõem a essa elevação criativa de potência não se dão de forma dicotômica, mas são constitutivos das trajetórias identitárias. Analisemos o orgulho de pertencimento à identidade Sem Terra como um exemplo do que falamos.

"A gente fica pensando, 'só o teórico estuda muito, o professor da universidade e tal', mas a gente, camponês, também consegue entender", expressa a militante 3. Esse orgulho identitário se dá em razão de um "outro" hostil, que desconfia da capacidade do camponês. Essa hostilidade se materializa no ambiente universitário por meio do "preconceito de achar que Sem Terra não tem direito a ser doutor... Teve confronto com os estudantes da universidade, [de eles nos chamarem] de 'Jeca Tatu', desses estereótipos que rotulam a gente", afirma a militante 2. Essa mesma militante, reagindo a esse ambiente hostil, revela:

havia momentos que a gente tinha que parar os professores porque, como eles vieram apaixonados pra ensinar numa turma social... "ah, vocês são maravilhosos", "vocês", "vocês"... E ali a gente fazia essa conversa, "aqui a gente é estudante. O nosso trabalho social é outra coisa"; então às vezes tinha um aconchego demais, que a gente tentava dizer que a gente tava lá pra se preparar profissionalmente... Tinha um pouco de tratar como coitadinho...

Essa reação nos possibilita perceber um tipo de mecanismo pelo qual o meio, cuja hostilidade faz nutrir o sentimento de estar "ocupando a universidade" (militante 2) (abrindo uma picada), configura-se como constitutivo das identidades. A militante em tela, que se percebe parte de uma "turma diferenciada" e, orgulhosamente, intenta elevar sua potência, termina por demandar um tratamento de igualdade: ser uma estudante que ali se prepara profissionalmente e é capaz de "entender" - assim, intransitivamente (universalizando o polo lógico do processamento da experiência). Absorve, ao menos parcialmente, valores estruturantes do espaço acadêmico e estranhos à intencionalidade de quem começa a abrir a picada na mata: por um lado, o valor de construção de trajetórias individuais de vida (já que ali, naquele espaço, "o nosso trabalho social é outra coisa") e, quase como uma consequência, a valoração de um conhecimento que vale por si só, que se "entende" e, por isso, pode ser acumulado.

Esse tipo de situação, que interdita a crença na existência de um sujeito coletivo coeso, pode dificultar ou tornar nebuloso o processo de articulação entre 
epistemologia e ontologia, na medida em que disperse o caráter coletivo do processamento da experiência. O sujeito coletivo MST, quando investe na "aquisição" do conhecimento científico - o que desvela a necessidade de se relacionar com o meio instituido - como um recurso à autoridade que este conhecimento goza em nossa sociedade, não o faz sem questionar o sentido político que venha a adquirir. Cuida, portanto, como vimos, para que "a luta" (a construção estratégica de trajetórias coletivas de vida) seja o crivo de validade do conhecimento.

Outro elemento que emergiu em nossas entrevistas, e que joga na dispersão (inclusive organizativa) do Movimento, foi o fato de os militantes, uma vez formados pelos cursos do PRONERA, passarem a ser atraídos por propostas no mercado de trabalho (privado e estatal). Perguntada sobre o que faz com que as pessoas se desviem do projeto coletivo do MST, a militante 2 não titubeia:

Sem muitos rodeios, é uma proposta financeira fora [do MST]. Então tem pessoas que têm essa necessidade familiar, como eu já falei antes, e como o Movimento não tem como garantir mensalmente $\mathrm{X}$, então "oh, terminei o curso, minha situação é essa, exige uma conversa”; mas há pessoas que são apostas erradas (que ninguém tem estrela na testa), que fazem o curso e se mandam porque receberam uma proposta financeiramente melhor; e pronto, aí a gente não tem como ter controle disso, foram apenas pessoas que a gente preparou pro mercado de trabalho.

Essa contradição entre a luta política coletiva e a luta individual pela reprodução da vida nos faz perceber que o sentido criativo pretendido pelo MST para a "alternância" não depende exclusivamente de sua intencionalidade política ou mesmo de sua relação conscientemente tensa com o meio instituído. É necessária a construção de esteios materiais concretos (terrenos ideologicamente férteis, como diria Laclau), capazes de imprimir eficácia e factibilidade estratégica ao seu investimento ideológico - é preciso, portanto, que se organize o mundo que se quer descrever, como nos ensinou Maingueneau. É nesse contexto que a dimensão econômica do social é chamada a ter um lugar importante em nossa análise.

A eficácia e factibilidade das estratégias pretendidas no processo de (re) orientação da experiência por meio do princípio da alternância parecem depender da construção de elos "funcionais" contra-hegemônicos que ofereçam aos militantes do MST aquele esteio material a que nos referimos. Em um país em que a "educação rural" é tida como dispensável para a reprodução do capital (Damasceno; Beserra, 2004, p. 77-78), sendo que o investimento nela não se demonstra historicamente atrativo, investir, no presente, em relações não capitalistas de produção é o que permite imprimir factibilidade ao sentido político pretendido ao princípio da alternância na tradição marxista. Essa percepção, ainda que não nos nossos termos, hoje está pautada no MST quando este se propõe a disputar o sentido de "desenvolvimento sustentável". Na perspectiva do Movimento, os assentamentos devem ser entendidos como "territórios sob a hegemonia do MST" (MST, s/d.a, p. 24) - o que implica resistir ao controle do processo produtivo no campo pelas grandes corporações internacionais, que contam com a colaboração do Estado e 
latifundiários tradicionais. Isso significa denunciar valores cruciais do modelo exportador: monocultura; mecanização; assalariamento; dependência de agrotóxicos, fertilizantes, hormônios e sementes transgênicas.

Ao assim delinear a ação estratégica, os termos que definem essa escolha para a redireção da experiência com alternância pelo MST são radicalmente distintos e até conflitantes - afinal se investe num sujeito condenado ao mais crasso desaparecimento - com os valores modernos europeizantes hegemônicos no marxismo. Esse rompimento com procedimentos estratégicos caros ao marxismo (vinculados a princípios que, sendo cultivados no polo epistemológico, fortaleciam formas organizacionais correspondentes [partidos políticos de massas] à estratégia adotada vis-à-vis certa topografia do social [Estado-nação como totalidade social]), conforme nosso argumento, em lugar de enfraquecer, fortalece uma tradição política (no caso, falamos da tradição socialista). Ao investir nos seus assentamentos como "áreas liberadas", a ação criativa do MST também desloca a "alternância" do sentido reformista do humanismo cristão universal, que se volta à estratégia de agregar o conjunto dos espaços sociais num todo coerente. O cristianismo no MST, trazendo o conflito para o cerne de sua ação político-educativa, permite que se aposte numa dimensão positiva, mas revolucionária, não sistêmica, de política.

Essas ações estratégicas são criativas apenas à medida que se criam esteios materiais, que ampliem o escopo de factibilidade das estratégias adotadas. Tal ampliação pode requerer a alteração dos termos que ditam os princípios de (re) orientação da experiência. Assim, a crença racionalista na possibilidade de manter a coerência entre princípio e prática pode resultar, contrariamente ao efeito desejado, em menor potência do sujeito criativo.

\section{CONCLUSÕES}

A ação educativa, uma vez constitutiva de sujeitos políticos, sem essência identitária, tem sua dimensão criativa inscrita em processos interativos (locais). Esses processos, para serem pensados em perspectiva contra-hegemônica, através do conceito de experiência, não podem vincular-se organicamente (em perspectiva sistêmica ou dialética) às lógicas hegemônicas inscritas no tecido social. A noção de unidade do mundo (estabilidade das totalidades sociais e naturalização de uma topografia que constitui suas partes) deve perder força explicativa e política, quando se investem em ações criativas que - desorganizando o encaixe entre epistemologia e ontologia - ampliam o campo de factibilidade dos discursos.

A experiência do MST com a "alternância" - aqui analisada em caráter ainda introdutório, mas suficiente para apontar pistas teóricas para pensar a dimensão "estratégica" das ações educativas contra-hegemônicas em outras bases -, ao trazer o conflito para o centro da ação educativa, propicia o entendimento de que o processo criativo de estruturação do social não deve ser entendido segundo abordagens abordagens exclusivamente microssociológicas (construtivismo). Se assim proceder, o analista interessado em ações contra-hegemônicas deixa capturar os processos interativos que estuda em lógicas macrossociais sedimentadas hegemonicamente. A 
correta ênfase no processo político-educacional, não podendo prescindir das relações concretas de poder que o envolve, deve ser posta em dimensão mesossociológica.

Quando o processamento da experiência é analisado por meio da compreensão de que os discursos são práticas que envolvem uma dimensão linguística e outra social, a presença do conflito na ação educativa exige uma disputa por (e pela construção de) espaços sociais alternativos (relativamente autônomos). Sendo relacionais, esses espaços, para manter aceso um éthos contra-hegemônico, têm de ser articulados a outros, que perpassam outras esferas e dimensões do social. A estruturação do social, nesse contexto, remete à existência de múltiplas realidades, mas os vetores delas resultantes mais apontam para uma retórica generalizada do que para processos capturáveis desde uma racionalidade superior que a tudo engloba - crença presente tanto em John Dewey (e na forma como se estruturou nosso sistema nacional de ensino) como no discurso educativo do MST - e, por que não dizer, na tradição de nossa educação popular.

A ação é criativa quando se desvencilha de ser momento interno de uma narrativa histórica única. A condição de possibilidade para tal desvencilhamento é a promoção de alterações no polo ontológico, que remete à construção de esteios materiais para as estratégias contingentemente construídas. Os processos interativos, sob essa ótica, teriam que aceder à condição coletiva, pois é por meio da construção de um "nós" que se pode pensar em comunidades discursivas e, consequentemente, nas formas organizativas que possibilitam sua materialidade.

Poderíamos falar de "experiência" como eixo de uma estruturação conflitiva do social. Esta, remetendo à impossibilidade de fechamento das totalidades sociais, tem uma continuidade sempre opaca e fugidia, impossível de ser interpelada por investimentos científico-racionais. Conduzir criativamente a experiência significa romper - assim como o faz o MST ao tensionar as modernas narrativas urbano-industriais - com a noção racionalista de cumulatividade na formulação de princípios. Isso porque os espaços que se constroem para imprimir factibilidade a nossas intenções - sendo relacionais, conflitivos e constitutivos de identidades - nos possibilitam perceber que os sujeitos, ao (re)conduzirem suas experiências, sendo instados a constituir aqueles espaços, igualmente se constituem. Parece ser difícil pensar estratégias pela abordagem aqui proposta sem indagar radicalmente a forma escolar hegemônica.

\section{REFERÊNCIAS}

Albuquerque, Eliana Borges Correia de; Morais, Artur Gomes; Ferreira, Andrea Brito. As práticas cotidianas de educação: o que fazem as professoras? Revista Brasileira de Educação, Rio de Janeiro: ANPEd; Campinas: Autores Associados, v. 13, n. 38, p. 252-264, maio/ago. 2008.

Andrade, Marcia Regina; Di Pierro, Maria Clara. As aprendizagens e os desafios na implementação do Programa Nacional de Educação na Reforma Agrária. In: Andrade, Marcia Regina; Molina, Mônica Castagna; Jesus, Sonia Meire Santos Azevedo de (Orgs.). Educação na reforma agrária em perspectiva: uma avaliação do Programa Nacional de Educação na Reforma Agrária. São Paulo: Ação Educativa; Brasília: PRONERA, 2004. 
ANDrioli, Antonio Inácio. Tecnologia e agricultura familiar: o movimento agroecológico como espaço de educação. ANPEd: Rio de Janeiro, 2007. Disponível em:< http://30reuniao.anped.org.br/trabalhos/GT03-2873-Int.pdf>. Acesso em: 3 mar. 2008.

Arroyo, Miguel. A educação básica e o movimento social do campo. In: Arroyo, Miguel; Caldart, Roseli Salete; Molina, Mônica Castagna (Orgs.). Por uma educação do campo. Petrópolis: Vozes, 2009.

Brasil. Ministério do Desenvolvimento Agrário (INCRA). Programa Nacional de Educação na Reforma Agrária (PRONERA). Manual de operações. Brasília: INCRA, 2004.

Brockmeier, Jens; Harré, Rom. Narrativa: problemas e promessas de um paradigma alternativo. Psicologia: reflexão e crítica, Porto Alegre: UFRGS, v. 16, n. 3, p. 525-535, 2003.

Caldart, Roseli Salete. A escola do campo em movimento. Currículo sem Fronteiras, Rio de Janeiro: [s.n.], v. 3, n. 1, p. 60-81, jan./jun. 2003. Disponível em: <http:// bibliotecadigital.conevyt.org.mx/colecciones/documentos/Catedra_Andres_Bello/ Agosto\%202007/Lecturas/escuela_del_campo.pdf>. Acesso em: 4 jul. 2011. . Pedagogia do Movimento Sem Terra. São Paulo: Expressão Popular, 2004.

Corcuff, Philippe. As novas sociologias: construções da realidade social. Tradução de Viviane Ribeiro. Bauru: EDUSC, 2001.

Damasceno, Maria Nobre; Beserra, Bernadete. Estudos sobre educação rural no Brasil: estado da arte e perspectivas. Educação e Pesquisa, São Paulo: USP, v. 30, p. 73 -89 , jan./abr. 2004.

Denzin, Norman Kent; Lincoln, Yvonna Sessions. Introduction: entering the field of qualitative research. In: (Eds.). Handbook of qualitative research.

Londres: Sage Publications, 1994.

Dewey, John. Vida e educação. In:Teixeira, Anísio (Org.). John Derwey: vida e educação. Tradução de Anísio Teixeira. Melhoramentos: São Paulo, 1971.

. Experiência e educação. Tradução de Renata Gaspar. Petrópolis: Vozes, 2010.

Eley, Geof. Forjando a democracia. São Paulo: Editora Fundação Perseu Abramo, 2005.

Ferraço, Carlos Eduardo. Cotidiano escolar, formação de professores(as) e currículo. 2. ed. São Paulo: Cortez, 2008.

Fuick, Uwe. Uma introdução à pesquisa qualitativa. Tradução de Sandra Regina Netz. 2. ed. Porto Alegre: Bookman, 2004.

Fonseca, Claudia. Quando cada caso NÃo é um caso: pesquisa etnográfica e educação. In: Reunião Anual da Anped, 21., 1999, Caxambu. Anais... Caxambu: UFRGS, 1999. Disponível em: <http://anped.org.br/rbe/rbedigital/RBDE10/RBDE10_06_ CLAUDIA_FONSECA.pdf $>$. Acesso em: 26 jun. 2011.

Giddens, Anthony; Turner, Jonathan Hugh. Introdução. In: (Orgs.). Teoria social hoje. Tradução de Gilson César Cardoso de Sousa. São Paulo: Editora UNESP, 1999.

JAY, Martin. Cantos de experiencia: variaciones modernas sobre un tema universal. Buenos Aires: Paidós, 2009. 
Joas, Hans. Pragmatismo. In: Outhwaite, William; Bottomore, Tom (Orgs.). Dicionário do pensamento social do século XX. Rio de Janeiro: Jorge Zahar, 1996.

Kilminster, Richard. Fenomenologia. In: Outhwaite, William; Bottomore, Tom (Orgs.). Dicionário do pensamento social do século XX. Rio de Janeiro: Jorge Zahar, 1996. Laclau, Ernesto. La razón populista. Buenos Aires: Fondo de Cultura Económica de Argentina, 2005.

Mouffe, Chantal. Hegemony e socialist strategy: towards a radical democratic politics. 2. ed. Londres: Verso, 2001.

Libâneo, José Carlos. Didática. São Paulo: Cortez, 1994.

Löwy, Michael. As aventuras de Karl Marx contra o Barão de Münchhausen: marxismo e positivismo na sociologia do conhecimento. 5. ed. rev. São Paulo: Cortez, 1994.

Macedo, Roberto Sidney. Etnopesquisa crítica, etnopesquisa-formação. Brasília: Liber Livro, 2006.

Maingueneau, Dominique. Novas tendências em análise do discurso. 3. ed. Tradução de Freda Indursky. Campinas: Pontes; Editora UNICAMP, 1997.

Mandel, Ernest. O lugar do marxismo na história. São Paulo: Editora Aparte, 1987.

Martins, Carlos Benedito. A pluralidade dos mundos e das condutas sociais: a contribuição de Bourdieu para a sociologia da educação. Em Aberto, Brasília: INEP, ano 9, n. 46, p. 59-72, abr./jun. 1990.

Mesquita, Rui Gomes de Mattos. Representação política e constituição de identidades coletivas: estudo sobre a narrativa petista. 2009.362f. Tese (Doutorado em Sociologia) - Universidade Federal de Pernambuco, Recife, 2009.

Movimentos sociais e escola pública: uma proposta para analisar projetos político-pedagógicos antagonísticos. Educą̧ão e Realidade, Porto Alegre: UFRGS, v. 35, n. 2, p. 207-227, 2010.

Molina, Mônica Castagna. Educação do campo: identidade e políticas públicas. In: Kolling, Edgar Jorge; Cerioli, Paulo Ricardo; Caldart, Roseli Salete (Orgs.). Brasília: Articulação Nacional por uma Educação do Campo, 2002. p. 7-9. (Coleção Por uma Educação do Campo, n. 4)

- A contribuição do PRONERA na construção de políticas públicas de educação do campo e desenvolvimento sustentável. 2003.282f. Tese (Doutorado em Desenvolvimento Sustentável) - Universidade de Brasília, Brasília, 2003.

Mora, José Ferrater. Dicionário de filosofia. Tradução de António José Massano e Manuel Palmeirim. Lisboa: Publicações Dom Quixote, 1978.

MST - Movimento dos Trabalhadores Sem Terra. Os assentamentos: diagnósticos e propostas de programas, s/d.a. Mimeografado.

Caderno de Educação, n. 8. s./d.b. Mimeografado.

Nogueira, Maria Alice. Educação, saber, produção em Marx e Engels. São Paulo: Cortez; Campinas: Autores Associados, 1990.

Ortiz, Renato. Um outro território: ensaios sobre a mundialização. São Paulo: Olho d’Água, 1999. 
Pessanha, José Américo. Filosofia e modernidade: racionalidade, imaginação e ética. Educação E̊ Realidade, Porto Alegre: UFRGS, v. 22, n. 1, p. 13-32, 1997.

Rıbeiro, Marlene. Pedagogia da alternância na educação rural/do campo: projetos em disputa. Educação e Pesquisa, São Paulo: USP, v. 34, n. 1, p. 27-45, jan./abr. 2008.

SADER, Eder. Quando novos atores entram em cena: experiências, falas e lutas dos trabalhadores da Grande São Paulo, 1970-80. Rio de Janeiro: Paz e Terra, 1988.

Santos, Boaventura de Souza. Pela mão de Alice: o social e o político na pós-modernidade. 10. ed. São Paulo: Cortez, 2005.

Sautu, Ruth; Boniolo, Paula; Dalle, Pablo; Elbert, Rodolfo. Manual de metodología: construcción del marco teórico, formulación de los objetivos y elección de la metodologia. Buenos Aires: CLACSO, 2005.

Schütze, Fritz. Pesquisa biográfica e entrevista narrativa. In: Weller, Wivian; Pfaff, Nicolle. Metodologias da pesquisa qualitativa em educação. Petrópolis: Vozes, 2010.

Silva, Lourdes Helena da. Educação do campo e pedagogia da alternância: experiência brasileira. Revista de Ciências da Educação. SÍSIFO, Lisboa: Universidade de Lisboa, n. 5, p. 105-112, jan./abr. 2008.

Somers, Margaret R. S.; Gibson, Gloria D. Reclaiming the epistemological "other": narrative and the social constitution of identity. In: Calhoun, Craig (Org.). Social theory and the politics of identity. Oxford: Blackwell, 1995.

Stedile, João Pedro. Entrevista. In: Stedile, João Pedro; Fernandes, Bernardo Mançano (Orgs.). Brava gente: a trajetória do MST e a luta pela terra no Brasil. São Paulo: Editora Fundação Perseu Abramo, 2005.

Teixeira, Anísio. A pedagogia de Dewey. In: (Orgs.). John Derwey: vida e educação. Tradução de Anísio Teixeira. São Paulo: Melhoramentos, 1971.

Teitelbaum, Kenneth; Apple, Michael Whitman.John Dewey. Currículo sem Fronteiras, Rio de Janeiro: [s.n.], v. 1, n. 2, p. 194-201, jul./dez. 2001.

Vendramini, Celia Regina. A experiência coletiva como fonte de aprendizagens nas lutas do Movimento Sem Terra no Brasil. Revista Lusófona de Educação, Lisboa: CeiEF, n. 6, p. 67-80, 2004.

\section{SOBRE OS AUTORES}

Rui Gomes de Mattos de Mesquita é doutor em sociologia pela Universidade Federal de Pernambuco (UFPE). Professor da mesma instituição. E-mail: gomesdemattosdemesquita.rui@gmail.com

Gisele Wanessa do Nascimento é graduada em pedagogia pela Universidade Federal de Pernambuco (UFPE).

E-mail: giselewa@hotmail.com 
